\title{
Pendidikan remaja putri di mata orang tua studi kasus Desa Wonosunyo Kabupaten Pasuruan
}

\author{
Ardhana Karina Reswari, Siti Malikah Towaf, Agus Purnomo* \\ Universitas Negeri Malang, Jl. Semarang No. 5 Malang, Jawa Timur, Indonesia \\ *Penulis korespondensi, Surel: agus.purnomo.fis@um.ac.id
}

Paper received: 03-02-2021; revised: 15-02-2021; accepted: 28-02-2021

\begin{abstract}
The purpose of this study was to analyze the vision of parents of young women in Wonosunyo Village, Gempol Subdistrict, Pasuruan Regency. This study uses a qualitative approach with a type of descriptive research. The data sources used are primary data sources and secondary data sources. There are three data collection techniques in the study, namely interviews, observation, and documentation. The conclusion of this study is that education is an insignificant thing when parents and children agree that the most important thing is to work and move on. Parents who cannot finance their children's education due to low income. Low income is felt not to be able to afford school fees, pocket money, to provide transport money. The desire to escape poverty is to marry off his child. Marrying their children at an early age is a family's desire that must be realized to fulfill a better and better life expectancy. The desire to benefit from marrying her child at an early age is the hope of every parent.
\end{abstract}

Keywords: drop out; young women; early marriage.

\begin{abstract}
Abstrak
Penelitian ini bertujuan untuk menganalisis visi orang tua remaja putri Desa Wonosunyo Kecamatan Gempol Kabupaten Pasuruan. Pendekatan kualittatif dengan jenis penelitian deskriptif digunakan untuk mencapai tujuan penelitianini. Sumber data primer dan sekunder digunakan dalam penelitian ini. Teknik pengumpulan data dilakukan dengan wawancara, observasi, dan dokumentasi. Penelitian ini berkesimpilan bahwa pendidikan menjadi suatu hal yang tidak penting ketika orang tua dan anak menyepakati yang terpenting adalah bekerja dan melanjutkan hidup. Orang tua yang tidak dapat membiayai pendidikan anaknya karena pendapatan yang rendah. Pendapatan yang rendah dirasa tidak akan mampu untuk membiayai sekolah, uang jajan, hingga memberikan uang transport. Keinginan untuk lepas dari jeratan kemiskinan adalah dengan menikahkan anaknya. Menikahkan anaknya di usia dini adalah keinginan keluarga yang harus diwujudkan untuk memenuhi harapan hidup yang lebih baik dan layak. Keinginan mendapat keuntungan dari menikahkan anaknya di usia dini adalah harapan setiap orang tua.
\end{abstract}

Kata kunci: putus sekolah; remaja; pernikahan usia dini.

\section{Pendahuluan}

Keluarga merupakan kelompok kecil dari pada masyarakat. Keluarga juga memiliki pemimpin serta anggota. Semuanya mempunyai pembagian tugas, hak, dan kewajibannya masing-masing. Keluarga juga merupakan saluran utama dalam mempelajari keyakinan, sifat mulia, komunikasi dan interaksi sosial, serta keterampilan hidup (Helmawati, 2016). Keluarga adalah tempat pertama dan utama dimana anak-anak belajar dan mendapat pendidikan.

Pendidikan adalah aset yang penting untuk masa depan seorang anak (Sari, Elvawati, \& Anggreta, 2013). Oleh karena itu, keluarga sangat berperan penting dalam memberikan pendidikan dan mendukung peningkatan kualitas pendidikan anaknya. Para orang tua diharuskan menjalankan fungsi sebagai pendidik dalam keluarga. Fungsi pendidik di dalam 
keluarga, di antaranya adalah untuk memberikan pengetahuan dan pengalaman tentang 1) ekonomi; 2) biologis; 3) kasih sayang; 4) pendidikan; 5) agama; 6) perlindungan; 7) sosialisasi anak; 8) rekreasi; dan juga 9) status keluarga (Helmawati, 2016).

Salah satu fasilitas yang diberikan orang tua yaitu menjalankan fungsi pendidikan agar seorang anak memiliki masa depan yang baik. Anak adalah generasi penerus bagi kelangsungan hidup di masa mendatang (Gunarsa, 2004). Sejalan dengan pernyataan tersebut, lingkungan keluarga memiliki peran penuh terhadap perkembangan anggota keluarganya, keberhasilan pendidikan anak acap kali dihubungkan dengan kondisi sikap dan pribadi orang, hubungan komunikasi dalam keluarga, dan role model dalam keluarganya (Hulukati, 2015).

Pendidikan mengasah anak-anak dengan pengetahuan dan pengalaman agar anak-anak memiliki kesadaran positif serta kemauan untuk menemukan, menentukan, dan mencapai tujuan mulia untuk dirinya dimasa yang akan datang (Wardani, 2016). Keterlibatan dari orang tua terhadap pendidikan anak, akan sangat berdampak terhadap keberhasilan anak di masa depan, baik dalam hal positif maupun negatif (Akbar, 2015). Dukungan dari orang tua sangat dibutuhkan demi tercapainya pendidikan yang baik bagi anaknya, tetapi tidak semua orang tua memiliki persepsi yang sama mengenai pentingnya pendidikan bagi anak.

Para orang tua tentunya memiliki rencana agar kehidupan anaknya menjadi lebih baik di masa depan. Akan tetapi hal ini sangat bergantung pada persepsi orang tua. Karena dengan persepsi orang tua yang buruk terhadap suatu bidang, akan menjadi buruk juga untuk anak. Oleh karena itu, persepsi baik orang tua terhadap pendidikan merupakan hal yang penting. Dengan persepsi yang baik ini pada umumnya orang tua akan berusaha untuk menyekolahkan dan memberikan pendidikan yang terbaik untuk anak-anaknya (Margaretha, 2015). Selaras dengan pernyataan tersebut orang tua mempunyai peranan besar dalam pengambilan keputusan mengenai boleh tidaknya seorang anak untuk mendapatkan pendidikan (Ambarwati, 2014). Jadi Peran dan persepsi orangtua terhadap pendidikan sangat penting dalam penentuan masa depan seorang anak, tidak terkecuali lembaga pendidikan yang berada di Desa Wonosunyo.

Desa wonosunyo berlokasi di Kecamatan Gempol, Kabupaten Pasuruan. Desa ini memiliki fasilitas pendidikan yang telah disediakan oleh lembaga pendidikan dari jenjang SD sampai SMK seperti Sekolah Dasar Negeri Wonsosunyo 1 dan 2, SMP Negeri 3 Gempol Satu Atap, dan SMK Taruna Bhakti (Data Kementerian Pendidikan dan Kebudayaan, 2018). Tersedianya fasilitas pendidikan ini merupakan salah satu bentuk perhatian pemerintah untuk menanggulangi besarnya angka putus. Namun, dengan fasilitas tersebut harapan pemerintah masih belum sepenuhnya terjadi.

Memperoleh pendidikan adalah hak setiap anak, dan orang tua berkewajiban memenuhi hak pendidikan tersebut. Nyatanya masih banyak dijumpai anak-anak putus sekolah seperti halnya di Desa Wonosunyo. Menurut data yang diperoleh dari lembaga pendidikan yang ada di Desa Wonosunyo yaitu SMP Negeri 3 Gempol Satu Atap yang telah berdiri sejak tahun 2011, pada lulusan angkatan pertama periode tahun 2013-2014 dari jumlah total angkatan yaitu 52 siswa-siswi, terdapat 30\% siswi putri setelah lulus dari jenjang Sekolah Menengah Pertama memilih untuk menikah, $15 \%$ siswa putra dan putri memilih untuk tidak melanjutkan pendidikan ke jenjang lanjut, dan 55\% memilih untuk melanjutkan pendidikan ke jenjang Sekolah Menengah Kejuruan yang ada di wilayah Kecamatan Gempol dan Kecamatan Pandaan (SMPN 3 Gempol, 2018). Dari data tersebut dapat diketahui bahwa jumlah siswa-siswi yang 
putus sekolah dan memilih menikah di usia dini mencapai 45\% sedangkan siswa-siswi yang pada akhirnya melanjutkan pendidikan yaitu 55\%. Dari perbandingan tersebut, maka dapat diperoleh fakta bahwa angka putus sekolah di Dewa Wonosunyo sangatlah tinggi. Oleh karena itu peneliti tertarik melakukan penelitian anak putus sekolah dengan fokus penelitian yaitu remaja putri yang memilih menikah di usia dini.

Putus sekolah adalah keluarnya seorang siswa dari lembaga pendidikan formal sebelum waktu kelulusannya (Istikasari, 2015). Putus sekolah akan berdampak besar dalam kehidupan anak mulai dari kekerasan sosial, keresahan ekonomi, dan moral di masa depan (Marfuah, 2016). Selaras dengan pernyataan tersebut dampak yang terjadi dari banyaknya anak putus sekolah akan berakibat pada sumber daya manusia Indonesia ke depan. Hal ini karena anakanak tersebut akan menjadi angkatan yang tidak berpendidikan, sehingga kebanyakan akan bekerja menjadi pekerja kasar atau pembantu rumah tangga (Istikasari, 2015).

Masalah lainnya yang timbul yaitu pernikahan usia dini di kalangan remaja atau usia remaja setelah lulus dari bangku SMP. Padahal semakin muda usia menikah, maka semakin rendah tingkat pendidikan yang di capai oleh seorang anak dan sebaliknya semakin tua usia menikah, maka semakin tinggi tingkat pendidikan seorang anak (Fadlyana \& Larasaty, 2009). Hal tersebut pada dasarnya ada kaitannya dengan pola asuh yang di anut orang tua, selain itu orang tua yang memiliki tingkat ekonomi rendah akan selalu tergesah-gesah untuk menikahkan anak perempuannya di usia muda (Astuty, 2013).Hal ini bertujuan agar beban anak akan segera dialihkan kepada menantunya.

\section{Metode}

Fokus penelitian ini adalah visi orang tua remaja putri di Desa Wonosunyo, Kecamatan Gempol, Kabupaten Pasuruan. Untuk mencapai hal tersebut, peneliti mengkaji penelitian ini menggunakan pendekatan kualitatif dengan jenis penelitian deskriptif. Data penelitian didapatkan dari sumber primer yaitu informan kunci dan pendukung. Sedangkan sumber sekunder diperoleh melalui informan kunci serta dokumen-dokumen yang dianggap penting dan menunjang penelitian ini. Sumber data primer dalam penelitian ini dipilih menurut kesesuaian tema yang diambil, yaitu terdiri dari informan pendukung dan informan kunci. Informan pendukung antara lain Kepala Desa Wonosunyo, Kepala Dusun Wonosunyo dan Kepala Sekolah SMPN 3 Gempol Satu Atap. Sedangkan informan kunci dalam penelitian ini adalah orang tua dan remaja putri yang memutuskan putus sekolah dan memilih menikah usia dini.

Untuk memperoleh data, wawancara, observasi, dan dokumentasi dilakukan ketika pengumpulan data. Bersamaan dengan hal tersebut, analisis data secara simultan dilakukan. Pandangan ini diadopsi dari model analisis data interaktif (Miles \& Huberman, 2009) yang terdiri dari pengumpulan data, reduksi data, penyajian data, dan kesimpulan/ verifikasi. Tahap-tahap penelitian yang dilakukan ada 3, yaitu pra lapangan, pekerjaan lapangan dan pelaporan. Tahap pra lapangan dilakukan sebelum peneliti melakukan penelitian di lapangan, di antaranya, menyusun rancangan penelitian, melakukan observasi awal lokasi penelitian, mempelajari buku ataupun jurnal literatur lain yang berhubungan dengan fokus penelitian, menyusun proposal serta instrumen penelitian, melakukan seminar proposal dan mengurus surat izin penelitian. Kemudian tahap pekerjaan lapangan dilakukan peneliti dengan mengumpulkan data dengan kombinasi berbagai teknik penelitian seperti observasi, wawancara, dan dokumentasi. Selanjutnya tahap terakhir adalah pelaporan, Tahapan 
penelitian ini dilakukan setelah data yang dikumpulkan disesuaikan dengan fokus penelitian yang telah ditentukan.

\section{Hasil dan Pembahasan}

Pendidikan menjadi tidak penting ketika orang tua dan anak sepakat, bahwa hal terpenting bagi mereka saat ini adalah melanjutkan hidupnya, dengan cara bekerja dan mencari uang. Keadaan ekonomi keluarga yang lemah, mengharuskan orang tua berterus terang kepada sang anak bahwa mereka tidak mampu memenuhi kewajiban pendidikan anaknya. Para orang tua yang tinggal di desa pada umumnya memiliki pemikiran agar anak perempuan tidak perlu mengenyam pendidikan yang terlalu tinggi bahkan sampai kuliah, yang terpenting sudah kemampuan dasar seperti bisa baca dan tulis. Setelah itu anak perempuan sudah bisa menikah. Orang tua tidak akan mempertimbangkan umur anaknya, adapun yang terpenting adalah kemampuan untuk memasak dan mengurus suami (Fitrianingsih, 2015). Para orang tua di desa pada umumnya memahami bahwa sekolah hanya sekedar untuk belajar membaca dan menulis agar tidak mudah tertipu dengan orang lain, sehingga orang tua akan memberhentikan sekolah anaknya dengan maksud sang anak akan lebih berguna jika membantu bekerja di sawah atau memelihara hewan ternak (Hikmah, Quraisy, \& Arifin, 2016).

Jeratan kemiskinan menjadi hal utama yang mendasari alasan pernikahan anak usia dini. Dalam pandangan mereka cara untuk lepas dari jerat kemiskinan adalah dengan menikahkan anaknya. Hal ini karena keterbebanan ekonomi orang tua terhadap anak perempuan, sehingga pernikahan adalah salah satu usaha untuk mempertahankan kehidupan keluarga (Rafidah, Emilia, \& Wahyuni, 2009).

Orang tua yang tidak dapat membiayai pendidikan anaknya karena pendapatan yang rendah, akan cenderung memberikan keleluasaan kepada anaknya jika sang anak meminta untuk menikah dan dinikahkan. Pendapatan yang rendah dirasa tidak akan mampu untuk membiayai sekolah, uang jajan, hingga memberikan uang transport pergi dan pulang sekolah. Hal ini karean faktor ekonomi adalah faktor penyokong utama dalam mendukung pendidikan. Jika ekonomi dalam keluarga memada, maka biaya pendidikan akan dapat terpenuhi. Sementara, apabila keadaan ekonomi orang tua kurang mampu, maka kebutuhan anak dalam bidang pendidikan tidak dapat terpenuhi (Yanti, 2017). Semakin baik kondisi ekonomi orang tua akan semakin tinggi pendidikan seorang anak begitu sebaliknya semakin rendah kondisi sosial dan ekonomi orang tua maka semakin rendah pendidikan seorang anak (Mucharom, 2018).

Menikah usia dini menjadi keinginan keluarga yang harus diwujudkan untuk memenuhi harapan hidup yang lebih baik dan layak. Namun, harapan tersebut tidak serta merta berjalan sebagaimana mestinya, dikarenakan menantu mereka memiliki pekerjaan sebagai pekerja serabutan dengan pendapatan di bawah Rp 1.000.000 per bulan. Kondisi ekonomi keluarga yang menikah usia dini rata-rata berpenghasilan di bawah Rp 1.000 .000 per bulannya, hal tersebut dikarenakan suami dari remaja putri tidak memiliki pekerjaan tetap (Dwi, 2014). Meskipun segera menikah merupakan perkara yang baik dan penuh kemaslahatan, tetapi tidak dengan istilah menikah secara tergesa-gesa (Adhim, 2002).

Keinginan mendapat keuntungan dari menikahkan anaknya di usia dini adalah harapan setiap orang tua. Menikah artinya memberikan keuntungan bagi orang tua melalui mahar pernikahan yang diberikan pihak laki-laki kepada pihak perempuan (Mahfudin \& Waqi'ah, 2016). Selain itu, ada sejumlah faktor yang juga mendorong terjadinya perkawinan usia muda 
di lingkungan masyarakat yaitu: a) ekonomi, b) pendidikan, c) faktor orang tua, d) media massa, e) norma. Adapun penjelasannya adalah sebagai berikut. Pertama, kehidupan keluarga yang berada di bawah garis kemiskinan merupakan alasan utama perkawinan usia muda, Dengan pernikahan usia muda anaknya beban orang tua akan berkurang, jika perkawinan dilakukan dengan orang yang dianggap mampu. Kedua \& ketiga, rendahnya tingkat pendidikan menyebabkan pengetahuan orang tua, anak, dan masyarakat hanya terbatas dan cenderung ingin segera menikahkan anaknya yang masih remaja. orang tua yang memiliki kekhawatiran terkena aib karena sangat dekat dengan pacar sehingga segera dinikahkan, juga merupakan salah satu faktor utama. Keempat, Banyaknya konten seks di media online menyebabkan anak remaja di era modern semakin permisif terhadap seks. Keempat, unsur norma memberikan pandangan kepada orang tua untuk takut jika anaknya dianggap perawan tua dan tidak bisa menikah (Yulianti, 2010)

Berdasarkan pemaparan di atas jika dikaitkan dengan teori pilihan rasional di bidang ekonomi, perilaku rasional tidak hanya bertindak menghasilkan suatu hasil tetapi juga memaksimalkan keuntungan (Coleman \& Fararo, 1992). Orang tua sebagai pelaku dan aktor, bertindak sebagai perencana untuk mencapai tujuan sesuai keinginan yang diharapkan. Tujuan tersebut adalah dengan memanfaatkan keadaan anaknya yang putus sekolah, orang tua memiliki rencana jika anak perempuannya sudah menginginkan menikah maka akan segera dinikahkan. Hal tersebut memiliki tujuan dan harapan dengan adanya seorang menantu diharapkan mampu membantu perekonomian keluarga, setidaknya beban ayah sebagai kepala keluarga akan beralih ke menantunya.

Tindakan sosial menurut Weber dibedakan menjadi empat tipe yaitu tindakan rasional instrumental, rasional nilai, rasional afektif, dan rasional tradisional (Damsar, 2015). Tindakan sosial yang dapat digambarkan yaitu adalah tindakan rasional instrumental, dimana orang tua sebagai aktor sudah mempertimbangkan suatu pilihan untuk memaksimalkan tujuan yang diharapkan. Tujuan tersebut yaitu orang tua menginginkan kehidupan keluarga membaik dari segi ekonomi dengan kehadiran menantu. Namun, keinginan tidak berjalan sesuai harapan, karena pada kenyataanya orang tua bahkan masih menjadi penopang ekonomi keluarga karena menantunya memiliki pekerjaan tidak tetap.

\section{Simpulan}

Pendidikan menjadi suatu hal yang tidak penting ketika orang tua dan anak menyepakati bahwa yang terpenting adalah bekerja dan melanjutkan hidup. Hal ini tidak lain adalah karena orang tua tidak dapat membiayai pendidikan anaknya karena memang pendapatannya yang rendah. Pembiayaan uang jajan hingga memberikan uang transport untuk anak yang sekolah dianggap menjadi tanggungan yang berat untuk orang tua. Keinginan untuk lepas dari jeratan kemiskinan adalah dengan menikahkan anaknya. Menikahkan anaknya di usia dini adalah keinginan keluarga yang harus diwujudkan untuk memenuhi harapan hidup yang lebih baik dan layak. Keinginan mendapat keuntungan dari menikahkan anaknya di usia dini adalah harapan setiap orang tua.

Berdasarkan pada kelemahan dan kekurang dari penelitian ini di masa yang akan datang dapat membahas pada cakupan yang berbeda seperti hamil di luar nikah dan pernikahan siri pada kalangan remaja di Desa Wonosunyo. Selain itu, dapat juga dilakukan penelitian yang serupa dengan subjek lokasi yang berbeda untuk memberikan bandingan antar daerah di Indonesia. 


\section{Daftar Rujukan}

Adhim, M. F. (2002). Indahnya Pernikahan Dini. Jakarta: Gema Insani Press

Akbar, M. A. (2015, September 29). Peran Orang Tua Terhadap Pendidikan Anak (Studi Empiris Pada Komunitas Pedagang Kaki Lima di Alun-Alun Kaliwungu Kecamatan Kaliwungu Kabupaten Kendal). Diambil kembali dari (https://lib.unnes.ac.id/24075/1/1201411092.pdf)

Ambarwati, D. L. (2014). Kajian Angka Putus Sekolah Tingkat Sekolah Menengah Atas (SMA) Berdasarkan Aksesbilitas, Kondisi Sosial Ekonomi, dan Perhatian Orang Tua di Kecamatan Pladaan Kabupaten Jombang. Malang: FIS UM: Skripsi tidak diterbitkan.

Astuty, S. Y. (2013). Faktor-Faktor Penyebab Terjadinya Perkawinan Usia Muda Dikalangan Remaja di Desa Tembung Kecamatan Percut Sei Tuan Kabupaten Deli Serdang. Jurnal Welfare State, 2(1)(Dari https://jurnal.usu.ac.id/index.php/ws/article/view/2140/1174)), 1-10.

Coleman, J. S., \& Fararo, T. (1992). Rational Choice Theory: Advocacy and Critique. London: SAGE Publication.

Damsar. (2015). Pengantar Sosiologi. Jakarta: PT Aditya Andrebina Agung.

Data Kementerian Pendidikan dan Kebudayaan. (2018, November 20). Jumlah PD Per Satuan Pendidikan (Sekolah) di Kecamatan Gempol. Dipetik November 20, 2018, dari (http://referensi.data.kemdikbud.go.id/pd_index.php?kode=051913\&level=)

Dwi, L. (2014). Analisis Kondisi Sosiodemografi dan Ekonomi Keluarga Yang Menikah Pada Usia Dini Di Kecamatan Wajak kabupaten Malang. Malang: FIS UM: Skripsi tidak diterbitkan.

Fadlyana, E., \& Larasaty, S. (2009). Pernikahan Usia Dini dan Permasalahannya. Jurnal Sari Pediatri, 11(2)(https://saripediatri.org/index.php/sari-pediatri/article/view/607/542.), 136-140.

Fitrianingsih, R. (2015). Faktor-Faktor Penyebab Pernikahan Usia Muda Perempuan Desa Sumberdanti Kecamatan Sukowono Kabupaten Jember, (skripsi). Dipetik Maret 20, 2019, dari (http://repository.unej.ac.id/bitstream/handle/123456789/73383/100210301056-RANI\%20FITRIANINGSIH-1-41.pdf?sequence=1)

Gunarsa, S. D. (2004). Dasar dan Teori Perkembangan Anak. Jakarta: Gunung Mulia.

Helmawati. (2016). Pendidikan Keluarga: Teoritis dan Praktis. Bandung: PT Remaja Rosdakarya.

Hikmah, L., Quraisy, H., \& Arifin, J. (2016). Kemiskinan dan Putus Sekolah. Jurnal Equilibrium Pendidikan Sosiologi, 4(2)(Dari https://media.neliti.com/media/publications/61063-ID-kemiskinan-dan-putussekolah.pdf), 164-173.

Hulukati, W. (2015). Peran Lingkungan Keluarga Terhadap Perkembangan Anak. Dipetik November 20, 2018, dari https://media.neliti.com/media/publications/114008-ID-peran-lingkungan-keluarga-terhadapperke.pdf

Istikasari, H. (2015). Keterkaitan 10 Konsep Dasar Geografi Dengan Perempuan Putus Sekolah Pada Jenjang DIKDAS 9 Tahun di Desa Tulungrejo Kecamatan Gandusari Kabupaten Blitar. Malang: FIS UM: Skripsi tidak di terbitkan.

Mahfudin, A., \& Waqi'ah, K. (2016). Pernikahan Dini dan Pengaruhnya terhadap Keluarga di Kabupaten Sumenep Jawa Timur. Jurnal Hukum Keluarga Islam, 1(1)(Dari http://journal.unipdu.ac.id/index.php/jhki/article/view/608), 33-49.

Marfuah, R. (2016). Kehidupan Anak Putus Sekolah di Kelurahan Kotalama Kecamatan Kedungkandang. Malang: FIS UM: Skripsi tidak diterbitkan.

Margaretha, S. (2015). Faktor-Faktor Penyebab Anak Tidak Melanjutkan Sekolah ke SMP dan SMA di Desa Lumbangsari Kecamatan Bululawang Kabupaten Malang. Malang: FIS UM: Skripsi tidak diterbitkan.

Miles, M. B., \& Huberman, A. M. (2009). Analisis Data Kualitatif, Buku Sumber Tentang Metode-Metode Baru. Jakarta: UI Press.

Mucharom, N. (2018). Analisis Kondisi Sosial Ekonomi Orang Tua terhadap Tingkat Pendidikan Anak di Kabupaten Jember. Jurnal Nusamba, http://ojs.unpkediri.ac.id/index.php/manajemen/article/view/11797/840), 1-13.

Rafidah, Emilia, O., \& Wahyuni, B. (2009). Faktor-Faktor yang Berhubungan dengan Pernikahan di Kabupaten Purworejo Jawa Tengah. Berita Kedokteran Masyarakat, 25(2)(Dari https://journal.ugm.ac.id/index.php/bkm/article/view/3564), 51-58. 
Jurnal Integrasi dan Harmoni Inovatif Ilmu-Ilmu Sosial (JIHI3S), 1(2), 2021, 249-255

Sari, C. R., Elvawati, \& Anggreta, D. K. (2013). Motivasi dan Strategi Keluarga Miskin Nagarai Talu, Kabupaten Pasaman Barat Melanjutkan Pendidikan Anak Ke Pergutuan Tinggi. Jurnal Ilmu Sosial Mamangan, 2(2)(http://ejournal.stkip-pgri-sumbar.ac.id/index.php/jurnal-mamangan/article/view/1371/593), 74-81.

SMPN 3 Gempol. (2018, komunikasi personal). Daftar Nama Alumni SMP Negeri 3 Gempol Satu Atap Tahun Pelajaran 2013-2014. Gempol: (Komunikasi Personal).

Wardani, D. Y. (2016). Analisis Penyebab Anak Putus Sekolah Pada Jenjang Pendidikan SD dan SMP di Desa Sidorahayu Kecamatan Wagir Kabupaten Malang. Malang: FIS UM.

Yanti, S. (2017). Faktor-Faktor Penyebab Anak Putus Sekolah Jenjang Pendidikan Dasar 9 Tahun (Studi di Desa Bonea Kecamatan Lasalepa Kabupaten Muna), (skripsi). Dipetik Maret 19, 2019, dari (http://sitedi.uho.ac.id/uploads_sitedi/A1A313075_sitedi_SKRIPSI.pdf)

Yulianti, R. (2010). Dampak Yang Ditimbulkan Akibat Perkawinan Usia Dini. Bagian Hukum Perdata, Fakultas Hukum, 3(1)(Dari http://infestasi.trunojoyo.ac.id/pamator/article/view/2394), 1-5. 